\title{
Sterilization, Capital Mobility and Interest Rate Determination for East Asia
}

\author{
Tony Cavoli \\ Queensland University of Technology
}

\begin{abstract}
This paper uses a simple open economy interest rate determination model to empirically examine an important aspect of pre-crisis monetary and exchange rate policy. It investigates whether sterilization of the reserve effects of capital inflows helped keep interest rates sufficiently high that they may have prolonged the inflow of capital. Despite the use of a pre-crisis sample in this study, the issues in this paper have relevance today given the recent trend in foreign capital inflow for Asia. The empirical section is concerned with the effect of reserve flows on the interest rate and is divided into two parts. The first tests for a contemporaneous effect of the basic model using OLS and IV methods. The second generalizes the model to assess for lagged effects by way of VAR analysis. The results show that there are some contemporaneous effects of sterilization on the domestic interest rate though the effects are stronger when estimating the lagged model.
\end{abstract}

- JEL Classification: F30, F32, F41

- Keywords: Sterilization, Capital flows, Interest Rates

\section{Introduction}

This paper uses a simple open economy monetary style model of interest rate determination to empirically examine the effect of sterilized intervention on the domestic interest rate in the East Asian region in the period prior to the Asian crisis. The model is based on Edwards and Khan (1985) (henceforth EK). This

\footnotetext{
*Corresponding address: School of Economics and Finance, Queensland University of Technology. Email: t.cavoli@qut.edu.au.

(C2007-Center for International Economics, Sejong Institution, All Rights Reserved.
} 
paper alters the conditions for money market equilibrium to include the effects of sterilization of capital inflows. This allows the model to assess whether sterilization was effective in placing upward pressure on domestic interest rates, thus keeping interest rates at the level that existed before the capital inflows.

Before the crisis, it is widely acknowledged that several East Asian economies experienced substantial and prolonged periods of foreign capital inflow. ${ }^{1}$ In the presence of largely managed exchange rates, monetary control of these economies was achieved by the sterilization of the reserve effects of capital inflows. In this paper, the focus is on the impact of the reserve effects of capital inflows on the domestic interest rate. In the absence of sterilization of these inflows, under a fixed exchange rate regime, a capital inflow should place downward pressure on interest rates. The presence of sterilization should, if successful, reverse this effect. Full (or complete) sterilization of the reserve inflow would maintain the interest rates at levels that existed pre-inflow. Indeed, if foreign capital is attracted to high domestic returns, successful sterilization may actually propagate further capital inflow by keeping interest rates from decreasing. ${ }^{2}$

Even though the paper studies the pre-crisis time period, the issues examined are relevant today. ${ }^{3}$ Consider Table 1 and Table 2 . Table 1 examines country level capital flows for the pre-crisis period. To put this period into context, Table 2 provides some recent trends for Asia in general. It is evident that capital inflows

Table 1. Capital Inflows as a percentage of GDP

\begin{tabular}{lcccc}
\hline & INDONESIA & MALAYSIA & PHILIPPINES & THAILAND \\
\hline FDI flows & 1.7 & 7.2 & 1.8 & 1.6 \\
Portfolio flows & 0.5 & 0.0 & 0.2 & 1.4 \\
Other & 3.0 & 2.9 & 2.1 & 8.5 \\
Total & 5.1 & 10.2 & 4.1 & 11.5 \\
$\Delta$ Reserves* & -1.7 & -5.1 & -1.8 & -4.3 \\
\hline
\end{tabular}

Source: Rajan and Siregar (2001) and IMF

Note: Negative sign means increase in reserves

\footnotetext{
${ }^{1}$ See, for example, Rajan and Siregar, 2001 and Rajan et al., 2001.

${ }^{2}$ The simultaneity that results from this two-way relationship is addressed in the empirical section (section 3) of this paper.
${ }^{3}$ The pre-crisis scenario is used also because there is a sufficient amount of data to assess, ex post, the existence of the extent and magnitude of the capital inflow episode and the extent of the sterilization of the reserve inflow.


Table 2. Net Private Capital Inflows 1994-2004

\begin{tabular}{lccccccccccc}
\hline & $1994^{*}$ & $1995^{* *}$ & 1996 & 1997 & 1998 & 1999 & 2000 & 2001 & 2002 & 2003 & 2004 \\
\hline Direct Investment & 44.7 & 55.8 & 53.4 & 56.5 & 56.1 & 66.4 & 67.4 & 60.5 & 53.8 & 70.0 & 77.2 \\
Portfolio Flows & 20.8 & 22.3 & 32.5 & 6.7 & 8.1 & 56.1 & 19.8 & -56.9 & -59.6 & 5.5 & 12.0 \\
Other & 4.7 & 21.2 & 33.5 & -25.5 & -116.4 & -113.9 & -91.7 & 6 & 31.2 & -22.8 & -9.4 \\
Total & 70.3 & 99.3 & 119.4 & 37.6 & -52.2 & 8.6 & -4.5 & 9.6 & 25.4 & 52.8 & 79.8 \\
\hline
\end{tabular}

Source: IMF World Economic Outlook September 2004, except for September 2003, ${ }^{*}$ and September 2002, ${ }^{* *}$. Data includes Emerging Asia and newly industrialising Asia categories of the IMF. All figures are in US Billions.

are increasing in the region after the capital flight brought about by the crisis. This is a key aspect of this paper. There is evidence to suggest that history is repeating itself in terms of the sustained inflow of capital to Asia. This brings to the fore the question of whether sterilisation is an effective and appropriate policy response post crisis (see Cavoli and Rajan, 2006, Rajan and Vostroknutova, 2006 and Ouyang, Rajan and Willett, 2006).

A key feature of the model is the relationship between capital mobility and sterilization. ${ }^{4}$ The more mobile is capital, the more the domestic interest rate will be influenced by external factors such as foreign interest rates and current and expected future exchange rate changes. As capital mobility decreases, the interest rate is driven more by domestic variables. It is this scenario involving imperfect capital mobility where sterilization policies might have an impact on interest rates. This presents an interesting policy implication in that sterilization may keep interest rates artificially high - thus prolonging the capital inflow. As such, not sterilizing may be the most appropriate policy to address the capital inflow episode. If capital mobility is sufficiently high such that it renders sterilization ineffective, the bet policy response to the inflow problem might be to employ capital controls.

The paper is set out as follows; Section 2 formalizes the relationship between sterilized intervention and capital mobility and assesses the effectiveness of sterilization in addressing the issue of sustained capital inflow. It is shown that the presence of high capital mobility and/or the presence of full sterilization of capital inflows neutralizes the effect of the reserve inflow on the domestic interest rate. In other words, high capital mobility renders sterilization ineffective but, where there is low to moderate levels of capital mobility, full sterilization reverses the

\footnotetext{
'The interaction between sterilization and capital mobility is captured by the 'irrelevance hypothesis' (see Frankel and Okwongu, 1996 and Kumhof 2000).
} 
downward pressure on interest rates that would arise from a capital inflow episode in a fixed exchange rate regime. Using the model as an organising framework, Section 3 will present some empirical estimates to investigate the extent and effectiveness of sterilization for the East Asian region using monthly observations from 1990-97. The selection of 1990 as the starting point is driven mainly by the fact that many of the countries in this sample had made substantial efforts to deregulate their financial systems during the 1980s thereby eliminating the necessity of modelling a structural break. The paper observes sterilization and capital mobility separately before evaluating the effect of reserve inflow on the domestic interest rate. The results indicate that, due mainly to the presence of high capital mobility or a high degree of sterilization, the contemporaneous effect of the reserves inflow on interest rates is small in magnitude. Some empirical results based on VAR analysis are also derived to examine whether there are any lagged effects of sterilization on interest rates. Section 4 provides some concluding comments.

\section{The Interest Rate Model and Some Implications}

\section{A. Model}

This section derives a model based on Edwards and Khan (1985) (EK) where the effects of sterilization are incorporated. Consider the following. ${ }^{5}$

$$
i_{t}=\psi i^{*}+(1-\psi) \tau_{t}, \quad 0<\psi<1
$$

Equation (1) is the structural interest rate equation from EK. It states that the domestic interest rate is a weighted average of international monetary conditions, $i^{*}{ }_{t}$ and domestic monetary conditions, $\tau_{t}$. The parameter $\psi$ refers to a country's level of capital mobility. As capital mobility increases, the domestic interest rate is determined increasingly by external factors and as capital mobility decreases, the domestic interest rate is determined more by domestic monetary conditions.

The external factors, $i_{t}^{*}$, are measured by uncovered interest parity (UIP). This is expressed as follows:

$$
i_{t}^{*}=i_{t}^{f}+\left(e^{e}{ }_{t+1}-e_{t}\right)
$$

where $i_{t}^{f}$ is a foreign-currency interest rate with which to base UIP and $e_{t}$ is the log of the current exchange rate expressed as the domestic price of foreign currency.

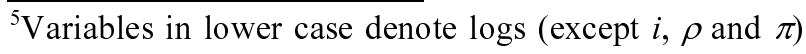


$e^{e}{ }_{t+1}$ is the expected depreciation of the (log) exchange rate in the next time period. As in many studies of capital mobility based on UIP, the risk premium is not explicitly captured in the model here, but is very much implied. This is particularly the case for developing economies where significant uncovered interest differentials (UIDs) are found to exist (de Brouwer, 1999 and Arias, 2001).

In the context of the model, $\tau_{t}$ is the domestic nominal interest rate that would exist if it were manipulated entirely by domestic monetary conditions. ${ }^{6}$ Hence, $\tau_{t}$ is a (shadow) interest rate that captures conditions of disequilibrium arising from excess demand or supply of money. As in EK, this shadow rate can be calculated in the following way:

$$
\tau_{t}=\rho+\pi^{e}{ }_{t+1}+\gamma\left(m_{t}^{d}-m_{t}\right)
$$

Equation (3) derives the domestically determined interest rate, $\tau$, as comprising of $\rho$, a full equilibrium real interest rate reflecting the long run marginal product of capital, the expected future inflation rate, $\pi_{t+1}^{e}$, and a term capturing monetary disequilibrium. Thus, any excess (shortfall) of log money demand $\left(m^{d}\right)$ relative to its supply $(m)$ will result in an increase (decrease) in the domestically determined interest rate.

The demand for money is similar to the one given in EK with the addition of a stock adjustment term. It depends on the full equilibrium interest rate, expected future inflation and income $(y)$.

$$
m_{t}^{d}-p_{t}=-\alpha_{1}\left(\rho+\pi_{t+1}^{e}\right)+\alpha_{2} y_{t}+\alpha_{3} m_{t-1}
$$

The effect of reserve inflow sterilization enters through the expressions for the money stock. The incorporation of sterilization yields the following: ${ }^{7}$

\footnotetext{
${ }^{6}$ The interpretation of variable like $\tau$ in Edwards and Khan, 1985, Haque and Montiel, 1991, Reisen and Yeches, 1993 and Dooley and Mathieson, 1994 and such others is that it is a 'closed economy' interest rate or shadow rate. This interpretation has to be refined in this context. Under this model, $\tau$ depends on (amongst others) the sterilization coefficient, $\lambda$. This implies that the capital account must not be completely closed for $\tau$ to be determined. An alternative definition of $\tau$ would be that is the domestic rate that would be determined entirely by domestic considerations where these considerations include the monetary policy stance taken by the central bank.

${ }^{7}$ Sterilization is captured by considering the relationship between domestic credit (D) and foreign reserves $(\mathrm{F})$ as follow: $\Delta D=\lambda \Delta F$. Substituting this into the familiar expression for the money base (in first differences), $\Delta M=\Delta D+\Delta F$, one obtains equation (5). Much of the literature using the EK model keep the money stock exogenous - in contrast to this paper.
} 


$$
\Delta M_{t}=(1+\lambda) \Delta F_{t}, \quad \lambda \leq 0
$$

where $\lambda$ is the sterilization coefficient. Equation (5), when expressed in log differences, becomes: ${ }^{8}$

$$
\Delta m_{t}=(1+l) \kappa \Delta f_{t}
$$

where: $\kappa=F_{t-1} / M_{t-1}$. The money stock can also be expressed as follows:

$$
m_{t}=\Delta m_{t}+m_{t-1}
$$

Substitution of (6) into (7) yields:

$$
m_{t}=(1+l) \kappa \Delta f_{t}+m_{t-1}
$$

The domestic interest rate, $i_{t}$ can now be calculated by substituting (8) and (4) into (3) to find $\tau_{t}$ and this can be substituted into (1): ${ }^{9}$

$$
i_{t}=\theta_{0}+\theta_{1} i_{t}^{*}-\theta_{2} \Delta f_{t}-\theta_{3} m_{t-1}+\theta_{4} \pi_{t+1}^{e}+\theta_{5} p_{t}+\theta_{6} y_{t}
$$

where

$$
\begin{aligned}
& \theta_{0}=(1-\psi)\left(1-\gamma \alpha_{1}\right) \rho \\
& \theta_{1}=\psi \\
& \left.\theta_{2}=[(1-\psi))(1+\lambda) \kappa\right] \\
& \theta_{3}=(1-\psi)\left(\gamma-\gamma \alpha_{3}\right) \\
& \theta_{4}=(1-\psi)\left(1-\gamma \alpha_{1}\right) \\
& \theta_{5}=(1-\psi) \gamma \\
& \theta_{6}=(1-\psi) \gamma \alpha_{2}
\end{aligned}
$$

\section{B. Implications}

What does the model imply about the behaviour of sterilization? The parameter of most interest is that for the reserve inflow, $\Delta f, \theta_{2}=[(1-\psi) \gamma(1+\theta) \kappa]$. The degree to which the sterilization of reserve inflows is successful in maintaining an upward pressure on the domestic interest rate is driven by three factors. These are considered briefly in turn.

The first factor influencing the effect of $\Delta f$ on $i_{t}$ is sterilization. $(1+\lambda)=0$

\footnotetext{
${ }^{8}$ From equation (5), divide both sides by $M_{t-1}$ and then multiply and divide both sides by $F_{t-1}$. Using the result, $\left(X_{t}-X_{t-1}\right) / X_{t-1} \ln \left(X_{t}\right)-\ln \left(X_{t-1}\right)$, we obtain equation (6).

${ }^{9}$ Cavoli and Rajan (2006) derive a similar model to analyse the effect of sterilization on the uncovered interest differential (UID).
} 
implies that $\lambda=-1$ and that there is complete sterilization of reserve flows as a change in reserves is fully offset by a(n opposite) change in domestic credit. If this is the case, the model asserts that there is no effect on the interest rate as full sterilization negates any monetary impact of a reserve flow and, as a result, interest rates also remain constant through the liquidity effect. The downward pressure on the interest rate due to a possible capital inflow has been reversed by sterilization and thus remains at the same level as before the inflow episode.

The second factor affecting the relationship between $\Delta f_{t}$ and $i_{t}$ is the adjustment parameter, $\gamma$. It is the extent to which a monetary disequilibrium affects the domestic interest rate. This effectively represents a measure of the sensitivity of the effects of sterilization on the interest rate. Clearly, a higher $\gamma$ indicates that the domestic interest rate is more sensitive to the authorities' sterilization activities. Its interaction with the other parameters is important.

The third factor is the level of capital mobility. For a given and constant $(1+\lambda)$, if the level of capital mobility, $\psi$ increases (or $(1-\psi)$ decreases), the effect of a reserve inflow on $i_{t}$ diminishes. For levels of capital mobility that are extremely high (nearing 1), the effect of capital inflows on the interest rate tends to zero irrespective of the extent of sterilization activity. This is because the interest rate is determined primarily by foreign interest rates and/or other external factors. ${ }^{10}$

\section{Estimating the Interest Rate Model}

\section{A. Data and Estimation}

The data is taken from the IMF IFS CD database taking monthly observations from 1990:1 to 1997:5 as the sample period. The sample excludes any effects of the crisis. Exchange rates are taken from line RF, interest rates, prices and output are taken from lines $60 \mathrm{~B}, 64$ and 66 respectively. $\Delta f$ is measured as $[\Delta F / F(-$ $1)]^{*} 100$ to measure the sensitivity to a percentage change in reserves and also

\footnotetext{
${ }^{10}$ In the context of this (monetary style) model that has no 'portfolio balance' type features, the capital mobility parameter may also capture characteristics more typically associated with imperfect asset substitution. These might include sluggish adjustment of returns following a shock (or a sterilized intervention) and risk factors. Hence, the capital mobility parameter may have a more general interpretation to include any factors that, in some way, hinder the convergence of the interest differential In a recent paper, Hutchison (2002) believes that capital mobility (more strictly interpreted) is a stronger factor in determining the effectiveness of sterilization than imperfect asset substitution. For imperfect asset substitution to have any meaningful effect, the relative asset quantities being moved must be enormous.
} 
Table 3. Sterilization Coefficients

\begin{tabular}{lccccc}
\hline & KOREA & THAILAND & INDONESIA & MALAYSIA & PHILIPPINES \\
\hline Sterilization & -1.11 & -0.91 & -0.76 & -0.94 & -0.97 \\
Coefficient & $(-3.81)^{\dagger}$ & $(-8.15)^{\dagger}$ & $(-7.07)^{\dagger}$ & $(-12.70)^{\dagger}$ & $(-10.24)^{\dagger}$ \\
\hline
\end{tabular}

Source: Cavoli and Rajan (2006). Results based on a sterilization equation as follows:

$\Delta D A_{t}=\lambda_{0}+\lambda_{1} \Delta F A_{t}+\lambda_{2} \Delta F A_{t-1}+\varepsilon_{t}$

The estimates presented are those for the contemporaneous sterilization coefficients, $\lambda_{1}$ as this is quite standard in estimations of this type.

Sample: 1990.1-1997.3 (monthly observations)

(†) denotes $1 \%$ significant level

because there were some observations of negative changes in reserves. ${ }^{11}$ Expected inflation is measured as $[\log (\mathrm{CPI}(12))-\log (\mathrm{CPI})]^{*} 100, m_{t-1}$ is $\log (\mathrm{MB}(-1))$, and output and CPI are measured in logs. The equation is based on Equation (9) and is estimated using OLS and TSLS. It includes a lagged dependent variable term to soak up the substantial amounts of serial correlation in the data and are estimated using Newey-West heteroskedastic-robust standard errors. OLS and Two-Stage Least Squares (TSLS) results for this are presented in Table 4 and are discussed in the next section. TSLS is the preferred method for this exercise to attempt to remove the possible bias resulting from the endogeneity of $\Delta f$ arising from its relationship with domestic assets and the nominal interest rate through the monetary offset coefficient (see Kouri and Porter, 1974, Obstfeld, 1982, Frankel and Okwongu, 1995, Moreno, 1996, Bond, 1999, Emir et al., 2000 and Mark, 2001 for a description). The instruments used in the TSLS regressions are the regressors from the OLS model, $\Delta d$ - which is measured as $[\Delta D / D(-1)]^{*} 100$ and the trade balance as per Bond (1999) and Mark (2001). ${ }^{12}$ The subsequent analysis is based on the TSLS results - the OLS estimates are provided merely for completion. All estimates were subject to the Breusch-Godfrey LM test for higher order serial correlation (Godfrey, 1988), White's test for heteroskedasticity and the Engle ARCH LM test for the existence of ARCH processes (Engle, 1982) and the Ramsey RESET test for general specification. For the most part, there were no significant ARCH coefficients except for Malaysia, but the model estimated remains Least Squares due to the fact that estimation in an ARCH model does not materially alter the value of the parameters for $i^{*}$ and $\Delta f$. The interest rate is

\footnotetext{
${ }^{11} \mathrm{~F}$ is defined as Net Foreign Assets and is calculated by subtracting IFS line 16C from IFS line 11.

${ }^{12} \mathrm{D}$ measured by net domestic assets (IFS line $14-F$ as calculated above). The trade balance is used to proxy for the current account for which monthly data is difficult to obtain for the sample used here.
} 
Table 4. Interest Rate Model-Capital Mobility and Domestic Influences Dependent Variable: Money market Rate, $i_{t}$,

\begin{tabular}{lcccccccccc}
\hline & \multicolumn{2}{c}{ KOREA } & \multicolumn{2}{c}{ THAILAND } & \multicolumn{2}{c}{ INDONESIA } & \multicolumn{2}{c}{ MALAYSIA } & \multicolumn{2}{c}{ PHILIPPINES } \\
\hline & OLS & TSLS & OLS & TSLS & OLS & TSLS & OLS & TSLS & OLS & TSLS \\
\hline \multirow{2}{*}{ Const } & 19.17 & 14.99 & -65.86 & -12.32 & -16.97 & -21.71 & 0.82 & 5.17 & 90.77 & 101.89 \\
& $(2.67)^{\dagger}$ & $(0.96)$ & $(-1.34)$ & $(-0.27)$ & $(-1.11)$ & $(-1.10)$ & $(0.19)$ & $(0.51)$ & $(2.56)^{* *}$ & $(2.72)^{\dagger}$ \\
\hline$i^{*}$ & 0.34 & 0.39 & 0.59 & 0.83 & 0.36 & 0.56 & 0.03 & -0.13 & -0.15 & -0.12 \\
& $(2.65)^{\dagger}$ & $(1.95)^{*}$ & $(2.35)^{* *}$ & $(2.77)^{\dagger}$ & $(2.38)^{* *}$ & $(1.66)^{*}$ & $(0.82)$ & $(-0.59)$ & $(-0.21)$ & $(-0.17)$ \\
\hline \multirow{2}{*}{$\Delta \boldsymbol{f}_{\boldsymbol{t}}$} & -0.06 & 0.02 & 0.05 & -0.03 & 0.03 & 0.27 & -0.03 & -0.11 & -0.001 & -0.01 \\
& $(-2.08)^{* *}$ & $(0.10)$ & $(0.44)$ & $(-0.20)$ & $(0.97)$ & $(1.75)$ & $(-3.68)^{\dagger}$ & $(-0.92)$ & $(-0.52)$ & $(-0.94)$ \\
\hline \multirow{2}{*}{$m_{t-1}$} & -6.47 & -6.37 & -8.75 & -3.53 & 1.92 & 7.98 & -0.17 & -0.81 & 3.41 & 3.83 \\
& $(-4.70)^{\dagger}$ & $(-4.71)^{\dagger}$ & $(-1.43)$ & $(-0.62)$ & $(0.62)$ & $(1.58)$ & $(-0.70)$ & $(-1.00)$ & $(0.51)$ & $(0.55)$ \\
\hline \multirow{2}{*}{$\pi_{\boldsymbol{t}+\boldsymbol{1}}$} & -0.40 & -0.37 & 0.44 & 0.33 & -1.52 & -7.72 & -0.002 & -0.05 & -0.55 & -0.60 \\
& $(-4.40)^{\dagger}$ & $(-2.95)^{\dagger}$ & $(2.03)^{* *}$ & $(1.34)$ & $(-0.59)$ & $(-1.96)^{* *}$ & $(-0.10)$ & $(-0.58)$ & $(-1.91)^{*}$ & $(-1.84)^{*}$ \\
\hline \multirow{2}{*}{$p_{t}$} & 13.22 & 14.94 & 24.83 & 6.25 & -3.96 & -16.84 & -0.17 & -0.76 & -24.25 & -30.46 \\
& $(3.22)^{\dagger}$ & $(2.12)^{* *}$ & $(1.40)$ & $(0.37)$ & $(-0.52)$ & $(-1.43)$ & $(-0.12)$ & $(-0.31)$ & $(-1.16)$ & $(-1.40)$ \\
\hline \multirow{2}{*}{$y_{t}$} & -2.23 & -3.38 & 0.43 & 0.70 & 3.94 & 5.17 & 0.35 & 1.60 & 4.17 & 7.64 \\
& $(-1.03)$ & $(-0.76)$ & $(0.06)$ & $(0.09)$ & $(0.89)$ & $(1.11)$ & $(0.79)$ & $(0.91)$ & $(0.43)$ & $(0.80)$ \\
\hline Adj $\mathrm{R}^{2}$ & 0.78 & 0.76 & 0.60 & 0.52 & 0.68 & 0.42 & 0.95 & 0.88 & 0.09 & 0.02 \\
\hline $\mathrm{DW}$ & 1.76 & 1.77 & 1.73 & 1.82 & 1.94 & 1.59 & 2.14 & 2.16 & 1.98 & 1.91 \\
\hline Obs & 89 & 89 & 88 & $77 *$ & 89 & 88 & 89 & 89 & 89 & 89 \\
\hline$*$
\end{tabular}

$*(* *)(\dagger), 10 \%(5 \%)(1 \%)$ significant levels, respectively

estimated in levels as they are $I(0)$ processes (except for Malaysia and weakly $I(0)$ for Korea) over the sample. ADF tests on the residuals for Malaysia and Korea indicate that the residuals are $I(0)$ implying that a cointegrating relationship existed in the models as estimated (see Appendix 1).

\section{B. Results}

\section{a) Contemporaneous Relationship}

In the context of the model in Section 2, the overall effect on the domestic interest rate centres around the interaction between the degree of capital mobility and the extent of reserve sterilization. Recall from Section 2 that if capital mobility is very high (around 1) then internal factors such as sterilization do not have an impact on the domestic interest rate. Sterilization can only affect interest rates under the model if capital mobility is less than perfect. 
While the extent of sterilization is not estimated here, there have been several recent studies that present broadly similar results. ${ }^{13}$ Table 3 presents some sterilization coefficients from Cavoli and Rajan (2006). The results indicate that the sterilization is high and very close to complete for most countries studied. The estimates for Korea suggest possible over-sterilization as the coefficient exceeds - 1 and those for Indonesia are lower than the others at -0.76 - an indication of partial sterilization.

The level of capital mobility is estimated hare and is given by the parameter $\grave{e}_{1}$. The results given in Table 4 are quite mixed. For the Philippines and Malaysia, the coefficient value is not significant. Korea's capital mobility coefficient is 0.39 , suggesting that, when taking into account any risk factors, around $1 / 3^{\text {rd }}$ of a foreign interest rate move is transmitted into domestic rates. Thailand records higher coefficient values at 0.83 and Indonesia's is 0.56 . In contrast to much of the literature on financial integration of late (see Cavoli et al., 2004 for a survey), the above results, with the exception of Thailand, suggest quite low levels of capital mobility. This might be due to the existence of a risk premium, capital controls and endogenous monetary policy (see McCallum, 1994 and Anker, 1999).

Under a scenario where capital mobility is imperfect and sterilization is close to complete, the model predicts that the domestic interest rate ought to be explained by domestic factors. Take, for instance, Thailand. The capital mobility parameter for Korea is 0.83 . This means the remainder (1-0.83) of the domestic rate that can be tentatively explained by domestic factors - such as sterilization. From Table 3, we also know that the degree of sterilization for Thailand is -0.91 . This would suggest that the sterilized intervention being undertaken should negate much, but not all, of the downward pressure placed on the interest rate by the capital flows. As a result, the value of $\theta_{2}$ should be close to zero and slightly negative. The existence of possible over-sterilization for Korea would suggest that $\theta_{2}$ is slightly positive.

Consider the value of $\theta_{2}$ in Table 4 . The sign and size of the effect of (\%) changes in $f$ on the domestic interest rate is consistent with the discussion above in that they are close to zero. For Korea, where the sterilization parameter is less than -1 , the effect of $\Delta f$ on $i_{t}$ is expected to be slightly positive and is so but it is statistically insignificant. For the other countries in the sample where sterilization is

${ }^{13}$ See Kwack (2001), Fane (2002), Cavoli and Rajan (2006). 
less than complete, the sign of $\theta_{2}$ should be slightly negative. This is indeed the case in Thailand. Only Indonesia's sterilization coefficient is statistically significant to any reasonable degree (but the incorrect sign). The lack of decisive results in this section motivate the analysis in the next section, which examines whether there is any lagged influence on the domestic interest rates.

\section{b) Using a VAR to test for a lagged relationship}

The model in Section 2 and subsequent analysis examines the contemporaneous relationships between sterilization, capital mobility and the domestic interest rate. In this section, we investigate whether there is a lagged relationship by presenting a Vector Autoregression (VAR) model on the variables of interest, $i, \Delta f$ and $i^{*}$. The VAR is of a standard form and is given by the following: ${ }^{14}$

$$
\begin{aligned}
& i_{t}=a_{10}+a_{11} i_{t}^{*}+a_{12} \Delta f_{i}+\sum_{j=1}^{m} \gamma_{1 j} i_{t-j}^{*}+\sum_{j=1}^{m} \beta_{1 j} \Delta f_{t-j}+\sum_{j=1}^{m} \alpha_{1 j} i_{t-j}+\delta_{1} X_{t}+\mu_{1 t} \\
& \Delta f_{t}=a_{20}+a_{21} i_{t}^{*}+a_{22} i_{t}+\sum_{j=1}^{m} \gamma_{2 j} i_{t-j}^{*}+\sum_{j=1}^{m} \beta_{2 j} \Delta f_{t-j}+\sum_{j=1}^{m} \alpha_{2 j} i_{t-j}+\delta_{2} X_{t}+\mu_{2 t} \\
& i_{t}^{*}=a_{30}+a_{31} \Delta f_{t}+a_{32} i_{t}+\sum_{j=1}^{m} \gamma_{3 j} i_{t-j}^{*}+\sum_{j=1}^{m} \beta_{3 j} \Delta f_{t-j}+\sum_{j=1}^{m} \alpha_{3 j} i_{t-j}+\delta_{3} X_{t}+\mu_{3 t}
\end{aligned}
$$

where $X_{t}$ is a vector of exogenous variables in the OLS and TSLS equations as outlined above.

The lagged effects of foreign interest rates, reserve changes and the domestic interest rate on the current domestic interest rate can be analysed by way of coefficient restrictions tests. ${ }^{15}$ Since the primary interest is on what determines the domestic interest rate, the focus is on the coefficients affecting $i_{t}$, Equation (10a). Equation (10b) and (10c) are essential in the analysis of a VAR because they determine the current and future values of $\Delta f$ and $i^{*}$ - which, in turn, impact on subsequent values of $i$. Table 5 reports the $\chi^{2}$ statistics of the Wald Test for

\footnotetext{
${ }^{14}$ The exogenous variables in equation (10) are left out of the VAR mainly to help with model identification. In addition, with the exception of Korea, they are largely insignificant. In order to identify the model, the Choleski decomposition is imposed, $a_{22}=a_{31}=a_{32}=0$. The restriction of $a_{22}=0$ corresponds to the 'instrument' equation in the TSLS regression and, as such, addresses the endogeneity issues as in the static model. ${ }^{15} \mathrm{~A}$ Wald test for restrictions on $g$ and $b$ are similar tests to the Granger Causality test for a selection of
lag lengths.
} 
Table 5. Test for Lagged Effects using VAR Model.

Wald Test for Coefficient Restrictions

\begin{tabular}{lcccccc}
\hline & \multicolumn{2}{c}{ Effect of Lagged $i^{*}$} & \multicolumn{2}{c}{ Effect of Lagged $\Delta f$} & \multicolumn{2}{c}{ Effect of Lagged I } \\
\hline & $\chi^{2}$ & Prob & $\chi^{2}$ & Prob & $\chi^{2}$ & Prob \\
\hline KOREA & & & & & & \\
\hline 12 lags & 14.24 & 0.29 & 11.50 & 0.49 & 42.97 & 0.00 \\
6 lags & 15.47 & 0.02 & 6.77 & 0.34 & 74.88 & 0.00 \\
3 lags & 12.61 & 0.01 & 5.71 & 0.13 & 92.78 & 0.00 \\
\hline THAILAND & & & & & & \\
\hline 12 lags & 6.14 & 0.91 & 7.42 & 0.83 & 11.55 & 0.48 \\
6 lags & 7.48 & 0.28 & 6.21 & 0.40 & 14.19 & 0.03 \\
3 lags & 1.61 & 0.66 & 8.36 & 0.04 & 13.24 & 0.00 \\
\hline INDONESIA & & & & & & \\
\hline 12 lags & 6.75 & 0.87 & 16.60 & 0.17 & 26.33 & 0.01 \\
6 lags & 7.58 & 0.27 & 12.94 & 0.04 & 31.12 & 0.00 \\
3 lags & 10.16 & 0.02 & 0.49 & 0.92 & 28.75 & 0.00 \\
\hline MALAYSIA & & & & & & \\
\hline 12 lags & 9.72 & 0.64 & 15.76 & 0.20 & 60.43 & 0.00 \\
6 lags & 6.27 & 0.39 & 23.66 & 0.00 & 281.40 & 0.00 \\
3 lags & 2.88 & 0.41 & 19.17 & 0.00 & 621.50 & 0.00 \\
\hline PHILIPPINES & & & & & & 0.89 \\
\hline 12 lags & 14.56 & 0.27 & 19.65 & 0.07 & 17.04 & 0.15 \\
6 lags & 4.54 & 0.60 & 5.00 & 0.54 & 10.39 & 0.11 \\
\hline lags & 2.29 & 0.51 & 1.08 & 0.78 & 0.89 & 0.83 \\
\hline Note: Based & & & & & & \\
\hline
\end{tabular}

Note: Based on the VAR model for $i, \Delta f$ and $i^{*}$ in equation (12). The sample is 1990:1 to 1997:5

coefficient restrictions for the VAR model. Three lag structures of the model are examined; $m=12,6,3$ months. The Wald Test is performed for each set of $m$ parameters for $\gamma_{1}, \beta_{1}$ and $\alpha_{1}$. The aim of the test is to ascertain whether the lagged effects of $i^{*}, \Delta f$ and the domestic interest rate, $i$ are significant in explaining the current value of $i$.

Let's look firstly at the results regarding the significance of restricting the coefficients of the lagged $i^{*}$ terms (the $\gamma_{1}$ terms). Generally, the omission of the $\gamma_{1}$ terms has little effect - regardless of the lag structure of the model. The exception is Korea, where the results are statistically significant for $m=6$ and $m=3$. Hence, for Korea, there is strong evidence suggesting an external influence on the domestic interest rate. For Thailand and Indonesia, recall from Table 4 that there is a significant contemporaneous relationship between $i^{*}$ and $i$. From Table 5 , it can be 
seen that the effect appears to be limited to the same time period and not be carried over as a lagged effect, except for Indonesia for a three-month lag. The weak lagged results for the Philippines and Malaysia seem to back up the weak contemporaneous results from Table 4.

The second set of results relate to the effect of restricting the $\beta$ coefficients. In other words, the test examines whether a change in reserves, one that may arise from sterilization, influences the domestic interest rate in the future. The results of the Wald Tests are quite mixed. For the most part, significant relationships are detected for Malaysia (3 and 6 months), Indonesia ( 6 months) and Thailand (3 months). The Philippines has a strong result for a 12-month lag. This is not a strange result if one thinks about the time it may take for a reserve flow to affect the money market rate. In fact, a delayed interest rate response to a reserve change is consistent with the weak contemporaneous results from Table 4.

The strongest Wald Test results are by far those testing for the effect of the lagged domestic interest rate. The exception here is the Philippines. This is expected as there is always going to be persistence in monetary variables. It is important to include the effect of the lagged dependent variable as it is an indication of the effect of domestic vs external variables. The more significant the effect of lagged $i$, the less likely it is that external determinants and, thus, capital mobility, play a material part in determining the domestic interest rate.

The VAR model can also be used to produce impulse response functions. As with the Wald tests, the focus is on the effect on the domestic interest rate, $i$. As such, Figure 1 presents the impulse responses of $i$ to shocks to the innovations in $i$, $\Delta f$ and $i^{*}$ for a 24 month time horizon. Model selection criteria (AIC) are employed to determine the appropriate lag length of the model for each country. ${ }^{16}$ The ordering used is $\left(i^{*}, \Delta f, i\right){ }^{17}$

The important relationship in the context of this study is the effect of an

\footnotetext{
${ }^{16}$ Lag lengths are 2 months for Korea and Thailand, 12 months for Indonesia and the Philippines and 1 month for Malaysia. Appendix 2 presents the impulse response functions for the model with 12, 6 and 3 month lags respectively. While not discussed in the main text, they are provided for the reader's convenience and for comparison to the Wald results. Also, it is worth pointing out that AIC is chosen because it favours longer lag lengths than BIC and the objective of this exercise is to keep as much explanatory power in the model as possible.

${ }^{17}$ The ordering is based on a Choleski decomposition on the VAR model as specified above. The decomposition is such that the contemporaneous effect of $i^{*}$ and $\Delta f$ is maintained as it is in equation (9). The value of $\Delta f$ is determined contemporaneously by $i^{*}$ but not $i$, and the value of $i^{*}$ not determined contemporaneously by either $\Delta f$ or $i$.
} 
Figure 1. Impulse Response Functions

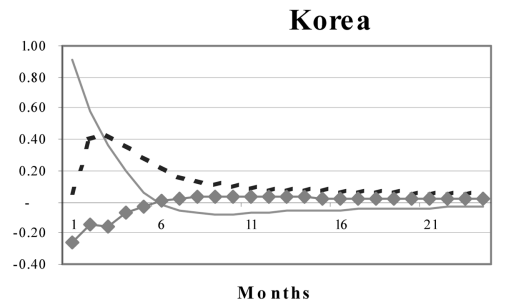

Thailand

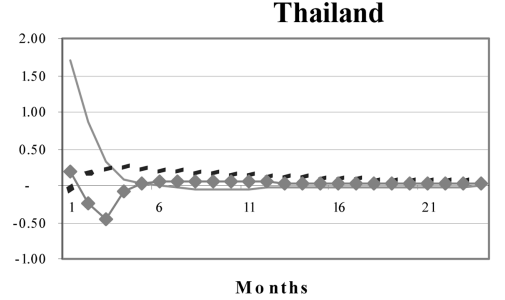

Indonesia
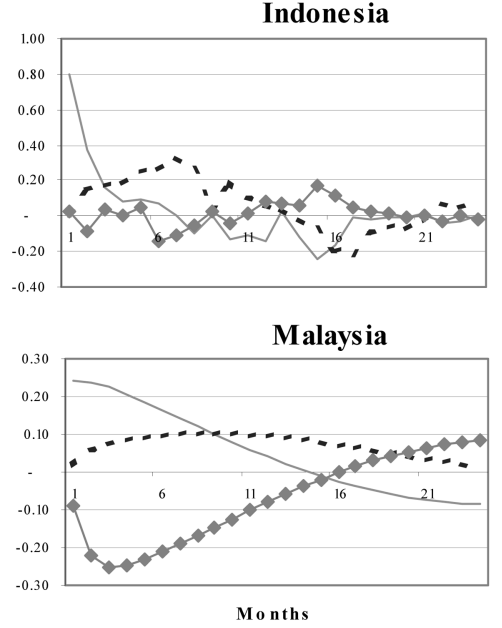

Philippines

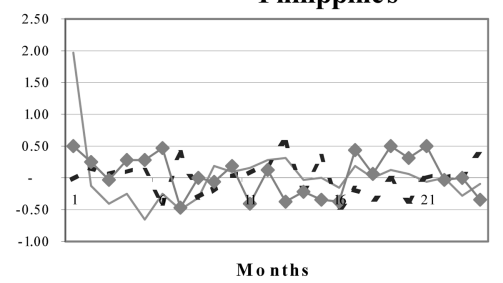

Figure 2. Variance Decomposition of $i$
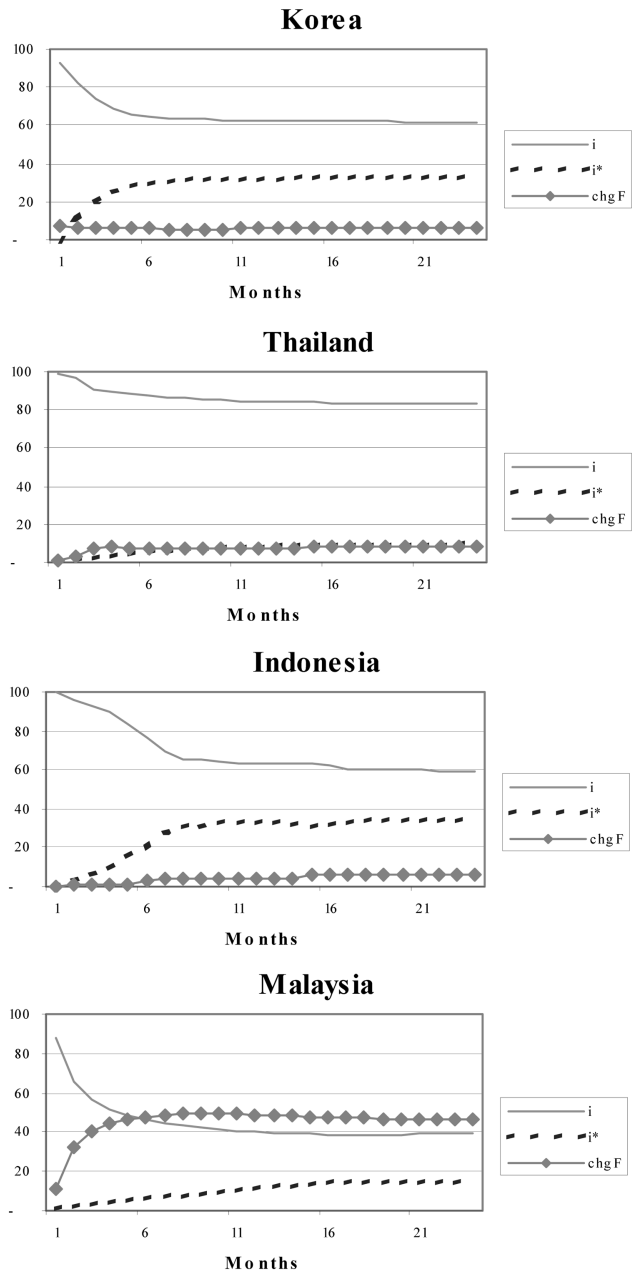

Philippines

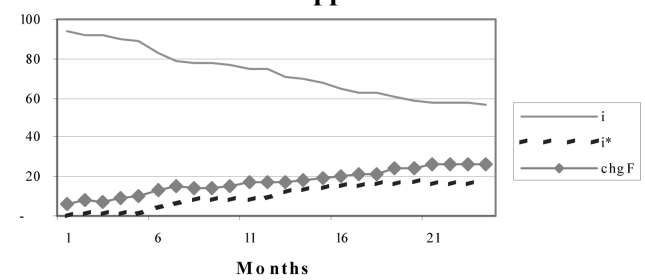

innovation in $\Delta f$ on $i$. For Indonesia and the Philippines, the relationship appears to fluctuate over time and, especially for the Philippines, the effect does not dissipate. In contrast, for Korea, Thailand and Malaysia, there is a negative initial effect on the domestic interest rate. For Thailand and Malaysia, this is consistent with a 
scenario of incomplete (albeit high) sterilization (see Table 3). The effect for Malaysia is especially strong as confirmed by the Wald test results. A reserve flow that is not fully sterilized will place downward pressure on the interest rate. The result for Korea is anomalous. Table 3 suggests that Korea over-sterilizes. This would suggest that the effect of a shock to reserve changes should have a positive effect on the interest rate.

To further assess the relative importance of lagged $i, i^{*}$ and $\Delta f$ in determining $i$, the standard VAR is used to analyse some variance decompositions. The lag length chosen for the decompositions and the ordering of the innovations is as above for the impulse responses. ${ }^{18}$ Figure 2 presents the variance decompositions for each country up to a 24 month forecast horizon. Each graph shows how a random innovation to $i, i^{*}$ and $\Delta f$-in relative terms - affects the variation of the domestic interest rate in the model.

The advantage of reporting the effect of an innovation in $i$ is that it addresses the relative amount of persistence in the model. The domestic interest is significantly driven by its own innovations. In fact, the line corresponding to $i$ never crosses the $i^{*}$ or the $\Delta f$ line. In other words, the effect of the domestic interest rate innovations on the domestic interest rate is generally stronger then the effect of the foreign interest rate and reserve changes for most countries tested.

In Malaysia, from about the five-month point, the effects of innovations in reserves and the domestic interest rate seem to influence the domestic interest rate in almost equal proportions. For the other countries, the relative effect is not as high, with the innovations to $i^{*}$ and $\Delta f$ each ultimately explaining a smaller proportion of the variation in $i$. This is an indication, first, that there is some dynamic relationship between reserves and the interest differential but not an overly strong one and, second, it indicates the strength of the persistence of the domestic interest rate.

\section{Concluding Remarks}

Motivated principally by the large and persistent capital inflows in East Asia before the crisis and the prospect of history repeating itself post-crisis, this paper has presented a simple theoretical model that examines the link between the central banks desire to sterilize capital inflows and the domestic interest rate in a fixed

\footnotetext{
${ }^{18}$ Appendix 3 contains variance decompositions for the model with 12, 6 and 3-month lag respectively.
} 
exchange rate regime. Under the model, the success of sterilization depends substantially on the level of capital mobility. If capital mobility is perfectly high, domestic rates are determined entirely by foreign influences and, therefore, sterilization is ineffective (irrelevance hypothesis). As such, the paper has investigated the possible connection between a central bank's desire to sterilize and the domestic interest rate.

The policy implications of this analysis are that, if effective through low capital mobility, sterilization may keep interest rates artificially high - thus prolonging the capital inflow. As such, the absence of sterilization may be the most appropriate policy to address the capital inflow episode. If capital mobility is sufficiently high such that it renders sterilization ineffective, the best policy response to the inflow problem might be to employ capital controls.

The interaction of sterilization and capital mobility is also investigated empirically. The paper estimates the sterilization and capital mobility coefficients individually from the structural equations in the model. These are then used to assess the overall effect on the domestic interest rate. The results presented show that, sterilization is mostly very high, with possible over-sterilization for Korea.

The model is generalized in order to show some lagged relationships between sterilization, capital mobility and the interest rates. Wald coefficient restriction tests show that lagged relationships exist strongly for Malaysia and, to a lesser extent, Thailand and Indonesia but not so for other countries. The impulse response functions show that a dynamic relationship does exist between reserve changes and the domestic interest rate and they provide some support for the Wald tests. Variance decomposition tests indicate that there is some relationship between reserve changes and interest rates but that interest rate shocks are highly persistent.

What do the results above imply about the effectiveness of sterilization and about the determinants of the interest rate non-convergence? There is evidence of imperfect capital mobility in most countries. This suggests that sterilization policies designed to maintain the interest rate at pre-inflow levels should have some effect. For the contemporaneous (TSLS) results using Equation (9), the principal determinant of the domestic interest rate is the foreign channel - the foreign interest rate, expected devaluation of the currency and a possible risk premium and these drive the level of capital mobility. Given that the period examined was a time of quite rigid exchange rates, it follows that the foreign (US) interest rate can be isolated as a main determinant. The VAR results (Equation 10) indicate that the interest rate is significantly determined by its own lag. That aside, the foreign 
channel is weaker in the VAR than the TSLS results and the effect of reserve flows are stronger in the VAR than in the least squares results. This is possibly suggestive that, for sterilization to be effective in influencing the interest rate, it may have to be administered in a smoothed fashion over a period of time.

\section{Acknowledgement}

The author thanks Kishen Rajan, Louise Allsopp and an anonymous referee for helpful comments on previous versions of this paper. All remaining errors are my own.

Received 21 March 2006, Accepted 25 September 2006

\section{References}

Anker, P., (1999), Uncovered interest parity, monetary policy and time-varying risk premia, Journal of International Money and Finance, vol.18 (6) December: 835-51.

Arias, G., (2001), Deviations from Uncovered Interest Parity, Lessons to be Drawn from Currency Crisis Models mimeo, CEFI, March

Bond T., (1999), Capital inflows to Asia: The role of monetary policy. In: The Mixed Blessing of Financial Inflows - Transition Countries in Comparative Perspective, (eds Gacs, J, Holzman R. and Wyzan M.), pp. 51-70. Edward Elgar, Chelten

Cavoli, T., R. Rajan and R. Siregar, (2004), A Survey of Financial Integration in East Asia. How Far? How Much Further to Go?, CIES Discussion Paper 0401, University of Adelaide, January

Cavoli, T. and R. Rajan, (2006), The Capital Inflows Problem in Selected Asian Economies in the 1990s Revisited: The Role of Monetary Sterilization. Forthcoming, Asian Economic Journal, December 2006

de Brouwer. G., (1999), Financial Integration in East Asia ${ }_{2}$ Cambridge: Cambridge University Press.

Dooley, M. and D.J. Mathieson, (1994), Exchange Rate Policy, International Capital Mobility, and Monetary Policy Instruments, in Glick, R. and M. Hutchison (eds), Exchange Rate Policy and Interdependence: Perspectives from the Pacific Basin. Cambridge Univ Press

Edwards, S. and M. Khan, (1985), Interest Rate Determination in Developing Countries. IMF Staff Papers 32, 377:403

Emir, O.Y., A. Karasoy and K. Kunter, (2000), Monetary Policy Reaction Functions in Turkey, mimeo, October

Engle, Robert F., (1982), Autoregressive Conditional Heteroskedasticity with Estimates of the Variance of U.K. Inflation, Econometrica, 50, 987-1008. 
Fane, G., (2000), Capital Mobility, Exchange Rates and Economic Crises. Edward Elgar Frankel, J. and C. Okongwu, (1995), Liberalized Portfolio Capital Inflows in Emerging Markets: Sterilization Expectations, and the Incompleteness of Interest Rate Convergence, International Journal of Finance and Economics, 1, 1-24

Glick R. and M. Hutchison, (2000), Foreign Reserve and Money Dynamics with Asset Portfolio Adjustment: International Evidence, Journal of International Financial Markets, Institutions and Money, 10, 229-47

Godfrey, L.G., (1988), Specification Tests in Econometrics, Cambridge University Press.

Haque, N. and P. Montiel, (1991), Capital Mobility in Developing Countries : Some Empirical Tests. World Development 19:10, 705-9

Hutchison, M., (2002), The Role of Sterilized Intervention in Exchange Rate Stabilization Policy, mimeo, June

Kouri, P. and M. Porter, (1974), International Capital Flows and Portfolio Equilibrium, Journal of Political Economy 82:3, 443-67

Kumhof. M., (2000), Sterilization of Short-Term Capital Inflows - Through Lower Interest Rates?, Mimeo, Stanford University

Kwack, S., (1994), Sterilization of the Monetary Effects of Current Account Surpluses and its Consequences: Korea 1986-1990, in Glick R. and M. Hutchison (eds), Exchange Rate Policy and Interdependence: Perspectives from the Pacific Basin, Cambridge Univ Press

(2001), An Empirical Assessment of Monetary Policy Responses to Capital Inflows in East Asia Before the Crisis, International Economic Journal, 15, 95-113

McCallum, B.T., (1994), A Reconsideration of the Uncovered Interest Parity Relationship, Journal of Monetary Economics, 33, 105-32

McLeod R.H., (1998), Indonesia, in McLeod and Garnaut, (eds), East Asia in Crisis: From Being a Miracle to Needing One, Routledge

McLeod, R.H. and R. Garnaut, (eds), (1998), East Asia in Crisis: from being a miracle to needing One. Routledge

Mark, N.C., (2001), International macroeconomics and Finance: Theory and Econometric Methods, Blackwell

Montiel. P and C. Reinhart, (1999), Do Capital Controls and Macroeconomic Policies Influence the Volume and Composition and Capital Flows? Evidence from the 1990s, mimeo

Moreno, R., (1996), Intervention, Sterilization and Monetary Control in Korea and Taiwan, Federal Reserve Bank of San Francisco Economic Review, 3, 23-33

Obstfeld, M., (1982), Can We Sterilize? Theory and Practice, AEA Papers and Proceedings, 72, 45-9

Ouyang, A., R. Rajan and T. Willett, (2006), Managing the monetary consequences of reserve accumulation in Asia, mimeo (August).

Rajan, R.S. and R. Siregar, (2001), Private Capital Flows in East Asia: Boom, Bust and Beyond, in G. de Brouwer (ed) Financial Markets and Policies in East Asia, Routledge, 
Rajan, R.S., R. Siregar and I. Sugema, (2001), Why Was There a Precrisis Capital Inflow Boom in Southeast Asia?, mimeo, August

Rajan, R. and E. Vostroknutova, (2006), Growing and managing risks through capital flows, mimeo, The World Bank

Reisen, H. and H. Yeches, (1993), Time Varying Estimates on the Openness of the Capital Account in Korea and Taiwan. Journal of Development Economics 41, 285-305

Warr, P.G., (1998), Thailand, in McLeod and Garnaut (eds), East Asia in Crisis: from being a miracle to needing One. Routledge

\section{Appendix 1}

1A. Augmented Dickey-Fuller (ADF) Test for Money Market Rates

\begin{tabular}{lccccl}
\hline Country & $\begin{array}{c}\text { ADF Test } \\
\text { Statistic }\end{array}$ & $\begin{array}{c}1 \% \\
\text { CV }\end{array}$ & $\begin{array}{c}5 \% \\
\text { CV }\end{array}$ & $\begin{array}{c}10 \% \\
\text { CV }\end{array}$ & Notes \\
\hline Korea & -3.22 & -4.06 & -3.46 & -3.16 & Intercept, trend, no lagged differences \\
Thailand & -3.60 & -3.51 & -2.89 & -2.58 & Intercept, no trend, no lagged differences \\
Indonesia & -2.96 & -3.51 & -2.89 & -2.58 & Intercept, no trend, no lagged differences \\
Malaysia & -1.72 & -3.51 & -2.89 & -2.58 & Intercept, no trend, 1 lagged difference \\
Philippines & -7.92 & -4.06 & -3.46 & -3.16 & Intercept, trend, no lagged differences \\
\hline
\end{tabular}

1B. ADF Test for Residuals of Interest Rate Regression (2.12)

\begin{tabular}{lccccl}
\hline \multirow{2}{*}{ Country } & $\begin{array}{c}\text { ADF Test } \\
\text { Statistic }\end{array}$ & $\begin{array}{l}1 \% \\
\text { CV }\end{array}$ & $\begin{array}{l}5 \% \\
\text { CV }\end{array}$ & $\begin{array}{l}10 \% \\
\text { CV }\end{array}$ & Notes \\
\hline Korea (OLS) & -8.43 & -2.58 & -1.94 & -1.62 & No intercept, no trend, no lagged differences \\
Korea (TSLS) & -8.33 & -2.58 & -1.94 & -1.62 & No intercept, no trend, no lagged differences \\
Malaysia (OLS) & -7.99 & -2.58 & -1.94 & -1.62 & Intercept, no trend, 2 lagged differences \\
Malaysia (TSLS) & -8.42 & -2.58 & -1.94 & -1.62 & Intercept, no trend, 1 lagged difference \\
\hline
\end{tabular}


Appendix 2a. Impulse Response Functions for 12, 6 and 3 lag model
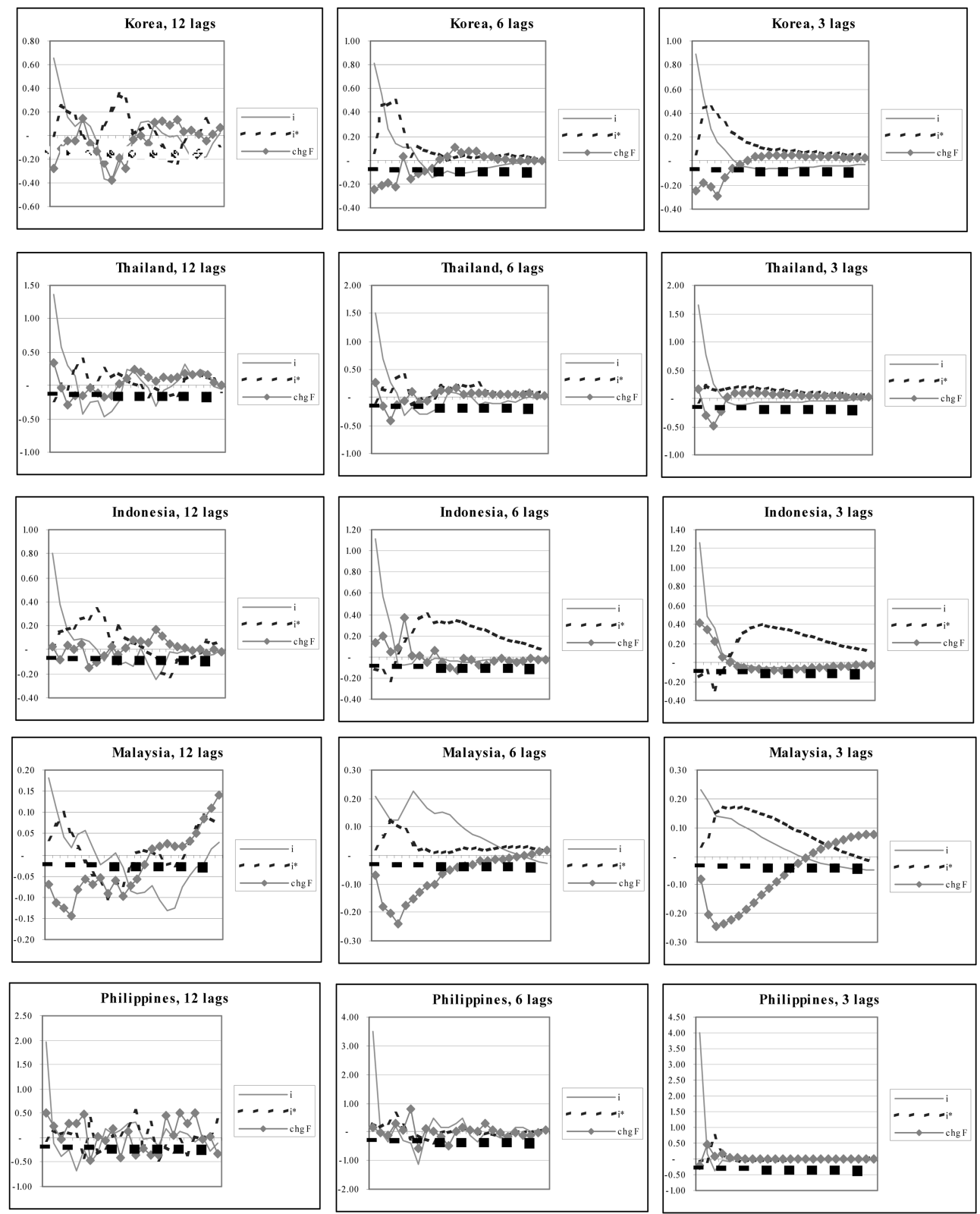
Appendix 2b. Variance Decompositions for 12, 6 and 3 lag model
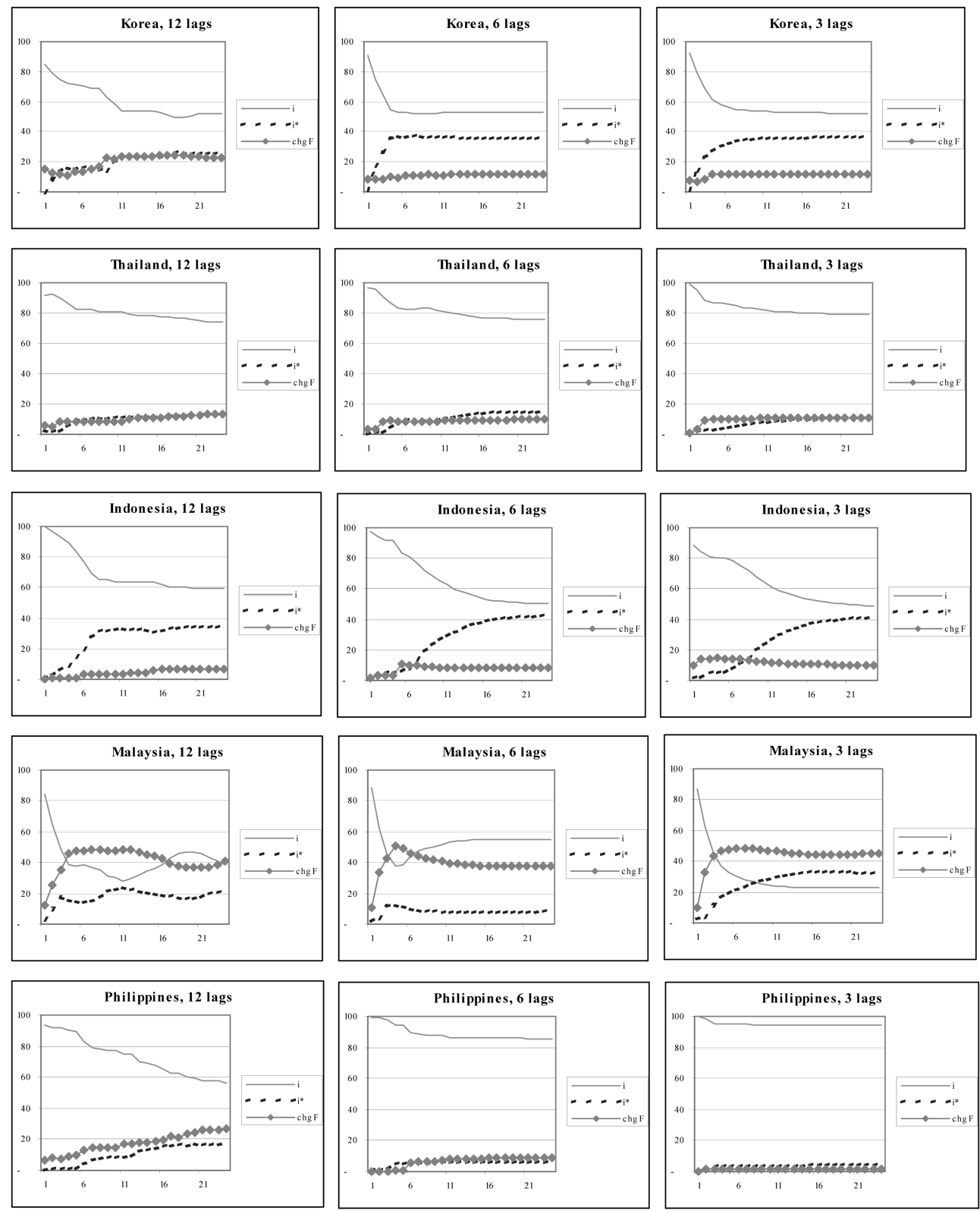